\title{
PLANOS NACIONAIS DE EDUCAÇÃO: TRAVESSIAS DA EDUCAÇÃO DE JOVENS E ADULTOS INTEGRADA COM A EDUCAÇÃO PROFISSIONAL
}

\author{
M. V. CACHO* e D. H. MOURA \\ Instituto Federal de Educação, Ciência e Tecnologia do Rio Grande do Norte \\ mylenna.vieira@ifrn.edu.br*
}

Artigo submetido em outubro/2015 e aceito em dezembro/2015

DOI: $10.15628 /$ rbept.2016.3521

\section{RESUMO}

Este artigo, baseado em análise documental e revisão bibliográfica, tem como objetivo discutir as relações entre a Educação de Jovens e Adultos (EJA) e a Educação Profissional no âmbito dos Planos Nacionais de Educação (2001- 2010; 2014 -2024). Para esse fim, contextualizamos as políticas públicas brasileiras direcionadas ao público daquela modalidade, delineamos a historicidade do PNE e refletimos sobre as metas e objetivos/estratégias apontadas nos Planos decenais, observando os interesses do mercado e perspectivas de concretização. $O$ embasamento teórico sobre políticas públicas e Estado dá-se em Santos (2010) e Poulantzas (2000); sobre Educação de Jovens e Adultos, em Christofoli (2010) e Jardilino e Araújo (2014). Para a fundamentação das discussões documentais sobre os Planos, utilizamos Saviani (1998), Horta (1982), Mendonça (2002), Dourado (2010) e Di Pierro (2010).

PALAVRAS-CHAVE: Planos Nacionais de Educação, Educação de Jovens e Adultos, Educação Profissional.

\section{NATIONAL PLANS OF EDUCATION: CROSSINGS EDUCATION OF YOUTH AND ADULTS WITH INTEGRATED PROFESSIONAL EDUCATION}

\begin{abstract}
This article, based on document analysis and literature review, aims to discuss relations between the Youth and Adult Education (EJA) and Professional Education under the National Plans of Education (2001- 2010; 2014 2024).To this end, we contextualize up Brazilian public policies to the public that mode, we outline to the historicity of the PNE and we reflect on the goals and objectives / strategies identified in the decennial plans,
\end{abstract}

noting the market's needs and implementation perspectives. The theoretical basis for public policy and state occurs in Santos (2010) and Poulantzas (2000); on Youth and Adult Education in Christofoli (2010) and Jardilino and Araújo (2014). In order to support the documentary discussions on the plans, use Saviani (1998), Horta (1982), Mendonça (2002), Dourado (2010) and Di Pierro (2010).

KEYWORDS: National Plans of Education, Youth and Adult Education, Professional Education. 


\title{
1 APRESENTAÇÃO
}

A Educação de Jovens e Adultos (EJA) atende a um público muito específico, que por razões diversas teve o direito à educação negado e mais tarde retorna às instituições de ensino em busca de concluir sua escolaridade. Em geral, são pessoas já inseridas ao mundo do trabalho ou que nele esperam ingressar e visam ascensão social ou profissional.

A história dessa modalidade de ensino foi construída sem articulação com o sistema educacional e sem ter contemplação pelas políticas públicas, tornando-se um reduto formal para onde se caminham os excluídos deste processo (CHRISTOFOLI, 2010). Assim, concordamos com Jardilino e Araújo (2014):

\begin{abstract}
Compreender o lugar que a EJA ocupa no sistema nacional de educação implica reconhecer que questões relacionadas à gestão, aos recursos e ao financiamento precisam ser discutidas à luz dos desafios e necessidades que a integração dessa modalidade de ensino pressupõe. $E$, ainda, que o sistema precisa garantir não apenas a oferta de oportunidades de acesso à escolarização, mas a permanência desses alunos jovens e adultos nas classes de EJA, bem como proporcionar qualidade no ensino e no material didático utilizado. (JARDILINO E ARAÚJO, 2014, p.113).
\end{abstract}

As políticas públicas surgem da interação entre o Estado e à sociedade, através de ações que fortaleçam a cidadania e atendam às necessidades da população. Para isso, necessitam de recursos para a sua aplicabilidade, o que as direcionam para as bases de políticas econômicas (SANTOS, 2010).

Poulantzas (1980) afirma que o papel do Estado em relação à economia modifica-se no decorrer dos diversos modos de produção e nos estágios e fases do próprio capitalismo. Nessa vertente, o Estado Brasileiro sempre esteve dependente da lógica do capital e pelo processo de acumulação por ela regido. Assim, o Estado por ser uma forma aberta e contraditória devido aos seus mecanismos de socialização/integração, trivialização/neutralização e repressão/exclusão, associado à ideologia capitalista promoveu/promove uma significativa exclusão social por atender aos interesses da lógica desse sistema. Nesse sentido, Poulantzas (1980) afirma que para:

entender o Estado como condensação material de uma relação de forças, significa entendê-lo como um campo e um processo estratégicos, onde se entrecruzam núcleos e redes de poder que ao mesmo tempo se articulam e apresentam contradições e decalagens uns em relações aos outros. (POULANTZAS, 1980, p.157).

Nessa perspectiva de interpretação do Estado, a exclusão pode ser percebida nas políticas públicas, que são formas de interferência do Estado, visando à manutenção das relações sociais de determinada formação social. As políticas públicas são o Estado em ação, agindo através de implantações de programas e projetos voltados para setores específicos da sociedade.

Nesse contexto, o início da década de 1990, pouca ênfase foi dada à Educação de Jovens e Adultos, o que tínhamos eram programas de governo de inspiração neoliberal e reformas nos sistemas de ensino que acompanhavam o processo de redefinição do papel do Estado em 
diferentes áreas. Destaca-se, nesse período a Lei de Diretrizes e Bases da Educação Nacional, no 9394/1996, que em seus artigos 37 e 38 amplia o contingente de jovens e adultos que podem ser atendidos pela EJA, assegurando gratuidade a quem não estudou na "idade regular", sem restrições quanto à idade mínima e aos estudos anteriores. A LDB vigente assegura ainda que os conteúdos curriculares, atendendo às especificidades desse alunado, deverão estar orientados para a prática social e para o trabalho, por meio de metodologias que considerem as experiências anteriores e o perfil dos discentes.

No entanto, a oferta da EJA pelos municípios e Estados apresenta sérios problemas relacionados às necessidades educacionais dos alunos, perpassando por implementação de classes, ampliação, material didático-pedagógico e à formação docente para atuar nessa modalidade.

No contexto político e econômico no final dos anos de 1990 e início dos anos 2000, as políticas públicas educacionais eram guiadas por regras do neoliberalismo decorrentes do processo de globalização. Dessa forma, valorizaram-se programas de capacitação em massa através do Plano Nacional de Qualificação do Trabalhador (Planfor) e o Programa de Expansão da Educação Profissional (Proep). Além, da desintegração do Ensino Médio com a Educação Profissional, de acordo com o Decreto n. 2.208/97, sancionado por Fernando Henrique Cardoso, que objetivava, com isso, conferir à educação profissional mais liberdade e flexibilidade para se adaptar às demandas do mercado de trabalho. Uma visão estritamente mercadológica, em detrimento de formação mais abrangente e comprometida com a elevação da escolaridade do jovem e do adulto trabalhador.

O emprego permanente ou continuado da EJA, através da função qualificadora, dificilmente tem materialidade histórica para ocorrer enquanto de maneira utópica pressupor que propiciará a todos a utilização de conhecimentos por toda a vida, sem garantir a efetividade das obrigações do Estado e ainda possibilitar aos alunos conhecimentos atrelados às necessidades imediatas do mercado e do mundo do trabalho.

Assim, este artigo tem como objetivo discutir as relações entre a Educação de Jovens e Adultos (EJA) e a Educação Profissional no âmbito dos Planos Nacionais de Educação (2001- 2010; 2014 -2024). Para esse fim, contextualizam-se as políticas públicas brasileiras direcionadas ao público dessa modalidade, delineia-se a historicidade do PNE e refletem-se sobre as metas e objetivos/estratégias apontadas nos Planos decenais, observando os interesses do mercado e perspectivas de concretização.

Diante disso, nos questionamos como os Planos Nacionais de Educação (PNE) - Lei no 10.172/2001 e Lei $\mathrm{n}^{\circ}$ 13.005/2014 - estão organizados e direcionados para atender as especificidades da Educação de Jovens e Adultos (EJA) atrelada à Educação Profissional (EP)?

As discussões deste texto encontram-se organizadas em três partes, além desta introdução. Inicialmente, apontamos uma breve historicidade do Plano Nacional de Educação (PNE); em seguida, analisamos algumas metas e objetivos/estratégias dos dois Planos diretamente relacionadas com a Educação Profissional (EP) para a Educação de Jovens e Adultos (EJA), contrapondo questões de avanços e de contradições. Nas considerações finais, refletimos sobre aspectos que devem ser considerados em torno da materialização do PNE no âmbito de nosso estudo. 


\title{
2 HISTORICIDADE DO PNE
}

Apesar de discutirmos neste artigo os PNE deste século, é importante historicizar os movimentos anteriores que deram origem a esses planos. Nesse sentido, foi com o Movimento dos Pioneiros da Educação Nova, em 1932, que a discussão sobre a necessidade de uma Plano Nacional de Educação ganhou força ao propugnar pela adoção de um plano geral de educação, de estrutura orgânica, a partir de um diagnóstico de uma realidade educacional sem unidade, fragmentária e desarticulada. Assim, tal Manifesto influenciou a Constituição brasileira de 1934, na medida em que esta estabeleceu como competência da União a fixação de um Plano Nacional de Educação, a coordenação e a fiscalização de sua execução em todo território nacional (SAVIANI,1998).

Segundo Mendonça (2002), com exceção da Constituição de 1937, devido ao golpe de Estado que instalou o Estado Novo, todas as constituições brasileiras, posteriores à de 1934, incluíram a ideia de um Plano Nacional de educação. Destaca-se também que a primeira Lei de Diretrizes Bases (LDB), no 4.024/1961, incumbia ao Conselho Federal de Educação (CFE) a missão de elaborá-lo. Com isso, em 1962, temos o primeiro PNE, não sob forma de lei, mas como uma iniciativa do Ministério da Educação e Cultura, aprovado por aquele Conselho. Objeto de revisões, conforme registrado mais tarde pelo primeiro PNE, Lei № 10.172/2001, aprovado por lei:

\begin{abstract}
Era basicamente um conjunto de metas quantitativas e qualitativas a serem alcançadas num prazo de oito anos. Em 1965, sofreu uma revisão, quando foram introduzidas normas descentralizadoras e estimuladoras da elaboração dos planos estaduais. Em 1966, uma nova revisão, que chamou Plano Complementar de Educação, introduziu importantes alterações na distribuição dos recursos federais, beneficiando a implantação de ginásios orientados para o trabalho e o atendimento de analfabetos com mais de dez anos. (BRASIL, 2001).
\end{abstract}

A Constituição de 1967 retoma a obrigatoriedade do Plano Nacional de Educação, sua elaboração deixou de ser do órgão normativo da educação e passou a ser inserindo nos planos nacionais de desenvolvimento (HORTA, 1982).

A Constituição seguinte, a de 1988, prevê o estabelecimento do PNE por lei, o seu artigo 214, por meio da Emenda Constitucional 59/2009, avança nas legislações anteriores ao garantir que

\begin{abstract}
A lei estabelecerá o plano nacional de educação, de duração decenal, com o objetivo de articular o sistema nacional de educação em regime de colaboração e definir diretrizes, objetivos, metas e estratégias de implementação para assegurar a manutenção e desenvolvimento do ensino em seus diversos níveis, etapas e modalidades por meio de ações integradas dos poderes públicos das diferentes esferas federativas [...]. (BRASIL, 2009)
\end{abstract}

Em 1996, a LDB, Lei no 9.394/1996, dispôs em seu Artigo 9o, Inciso I, que a União deveria elaborar o PNE, em colaboração com os Estados, o Distrito Federal e os Municípios, bem como, em seu Artigo 87, Parágrafo 1ํㅡㄹ , determinava que a União no prazo de um ano deve encaminhá-lo ao 
Congresso Nacional, com suas diretrizes e metas para os dez anos seguintes, em sintonia com a Declaração Mundial sobre Educação para Todos ${ }^{1}$.

Assim, percebemos que o primeiro PNE, legalmente instituído, deveria ter sido aprovado em 1997, ficando em vigência até 2006. Entretanto, isso só veio ocorrer quatro anos de "atraso" pela Lei no 10.172, de 9 de janeiro de 2001, que vigorou até 2010. Com a sua legitimidade, a responsabilidade jurídica foi gerada e as ações para o alcance das metas passaram a ser exigíveis.

No entanto, algumas críticas surgiram ao PNE 2001-2010, como as presentes na Exposição de Motivos no 33 (EXPMOTIV/MEC/2010/33), que destacaram a estrutura baseada no tripé "diagnóstico-diretrizes-metas", visto que as metas não vinham acompanhadas das estratégias necessárias para seu cumprimento.

A proposição do segundo PNE 2014-2024, aprovado por lei, passou a tramitar na Câmara dos deputados como Projeto de Lei no 8.035/2010, tendo durante os três anos e meio de tramitação até ser sancionado pela presidente Dilma Rousseff, em 25 de junho de 2014, a Lei no $13.005 / 2014$, a partir de um amplo debate, com participação dos atores sociais, por meio de audiências públicas e seminários, e requereu a construção de consensos ${ }^{2}$. 0 desafio é que sejam cumpridas as vinte metas, a partir de suas 254 estratégias.

Vemos, então, que a materialização do PNE está diretamente relacionada com o regime de colaboração entre sistemas e de cooperação federativa, tornando-se, assim, uma política de Estado que garanta a continuidade da execução e da avaliação frente às alternâncias governamentais e relações federativas. No entanto, a não concretização de algumas metas previstas no PNE 2001-2010, com prazos expirados, e a não articulação entre os entes federados para uma melhor organização e gestão da educação nacional, fazem-nos acreditar que (DOURADO, 2010, P.689) "o PNE não se converteu, efetivamente, em uma política de Estado, no sentido lato, mas constituiu-se em instrumento de luta em prol da construção das políticas". Porém, a construção do PNE vigente, resultado de ampla participação e deliberação coletiva da sociedade brasileira, é um marco para as políticas educacionais nacionais, resta-nos acompanhar, monitorar e exigir dos responsáveis o seu cumprimento.

\section{A EDUCAÇÃO DE JOVENS E ADULTOS INTEGRADA À EDUCAÇÃO PROFISSIONAL: O QUE DIZEM OS PLANOS NACIONAIS DE EDUCAÇÃO}

O percurso histórico das políticas públicas educacionais brasileiras direcionadas para a Educação de Jovens e Adultos (EJA) intensifica ainda mais os desafios a serem superados pelas Metas estabelecidas pelos Planos Nacionais de Educação. Temos nesse contexto indivíduos que não cumpriram trajetórias escolares ou que foram tolhidos durante a tentativa, ocasionando, expectativas de aprendizagem, habilidades e fases do desenvolvimento humano que deveriam ser amparadas por propostas pedagógicas bem específicas. Assim, analisaremos como estão dispostos nos Planos Nacionais de Educação (2001-2011; 2014-2024) as metas e os objetivos/estratégias

\footnotetext{
${ }^{1}$ Documento elaborado durante a Conferência Mundial sobre a Educação para Todos ( Jomtien, Tailândia - 1990) e que estabelece compromissos mundiais para garantir a todas as pessoas os conhecimentos básicos necessários a uma vida digna, visando uma sociedade mais humana e mais justa.

${ }^{2}$ Foram dezenove audiências públicas, dois seminários nacionais, catorze seminários estaduais na Câmara e oito audiências públicas no Senado.
} 
para esta modalidade em articulação com a Educação Profissional. $\quad$ O PNE 2001-2011 apresenta em sua estrutura para cada nível e modalidade de ensino o diagnóstico, as diretrizes, os objetivos e metas. O capítulo dedicado à EJA, tece um diagnóstico que reconhece a extensão do analfabetismo absoluto e funcional e sua desigual distribuição entre as zonas rural e urbana, as regiões brasileiras, os grupos de idade, sexo e etnia, apresentando dados da Pesquisa Nacional por Amostra de Domicílios (PNAD) nos anos de 1995 a 1997. Para Di Pierro (2010, p.944) "o Plano admitia ser insuficiente apostar na dinâmica geográfica e atuar apenas junto às novas gerações, propondo que as ações de escolarização atingissem também os adultos e idosos.".

Nas diretrizes, aderiu à concepção de educação continuada ao longo da vida, priorizando a atenção ao direito público subjetivo dos jovens e adultos ao ensino fundamental público e gratuito. Nesta parte, encontramos também como proposta a integração dos programas de educação de jovens e adultos com a educação profissional, destaca (BRASIL, 2001)

A importância da associação das políticas de emprego e proteção contra o desemprego à formação de jovens e adultos, além de políticas dirigidas para as mulheres, cuja escolarização têm, ademais, um grande impacto na próxima geração, auxiliando na diminuição do surgimento de "novos analfabetos". (BRASIL, 2001, p.44).

Percebemos que o foco das discussões centraliza-se na diminuição do analfabetismo dos jovens e adultos e sua elevação de escolaridade. Isso é ratificado quando verificamos os cinco objetivos e as vinte e seis metas apresentadas, destas, apenas duas se direcionam para a Educação Profissional, a 15 e a 17 ( BRASIL, 2001):

15. Sempre que possível associar ao ensino fundamental para jovens e adultos a oferta de cursos básicos de formação profissional.

17. Implantar, em todas as unidades prisionais e nos estabelecimentos que atendam adolescentes e jovens infratores, programas de educação de jovens e adultos de nível fundamental e médio, assim como de formação profissional. (BRASIL, 2001, p.46)

Para o cumprimento das metas, o PNE previa algumas ações contestáveis: como a cooperação entre as três esferas do governo e a sociedade civil organizada, porém o incremento de recursos financeiros era feito com os destinados ao ensino fundamental que não integravam o Fundo de Manutenção e Desenvolvimento do Ensino Fundamental e de Valorização do Magistério (FUNDEF); os programas de formação de educadores eram destinados para atuarem na alfabetização e séries iniciais e de responsabilidade dos Estados; a não fixação de estratégias ou metas específicas para reverter as desigualdades educativas observadas entre os grupos étnicoraciais e as populações rurais; e, mesmo prevendo um mecanismo de monitoramento periódico, mediante a divulgação e avaliação bienal dos programas da EJA, esta meta não foi concretizada.

No entanto, Di Pierro (2010, p.945) afirma que, mesmo sem essa concretização do monitoramento, os dois mandatos do Presidente Luís Inácio Lula da Silva, que ocorreram nos oito dos dez anos de vigência do Plano, eram perceptíveis a importância dada a esta modalidade através de sua inclusão nos mecanismos de financiamento, nos programas de assistência aos estudantes e criação de Programas direcionados a este público de ensino (alguns, articulados com à Educação Profissional), como o Programa Brasil Alfabetizado, o Programa Nacional de Inclusão 
de Jovens (PROJOVEM), Programa Nacional de Integração da Educação Profissional com a Educação Básica na Modalidade de Educação de Jovens e Adultos (PROEJA), Programa Nacional de Educação na Reforma Agrária (PRONERA) e o Programa Brasil Profissionalizado.

Apesar de todas essas ações, a taxa de analfabetismo da população com quinze anos ou mais não diminuiu durante a década. Segundo o Instituto Brasileiro de Geografia e Estatística (IBGE), essa taxa era de 12,4\% em 2001 e em 2008, tínhamos um índice de 10,00\%. O que representava uma preocupação para a proposta do próximo Plano e um desafio a ser superado.

Assim, o PNE 2014-2024, apresenta na Meta 9 a focalização para a elevação da taxa de alfabetização da população com quinze anos ou mais, na perspectiva de, até o fim da vigência do Plano, erradicar o analfabetismo absoluto e reduzir em cinquenta por cento a taxa de analfabetismo funcional de jovens e adultos brasileiros. Porém, apesar dessa Meta ser direcionada à EJA, nosso objeto de estudo neste artigo diz respeito à integralidade desta modalidade com à Educação Profissional, assim, nos deteremos em outra.

Iniciaremos, então, partindo da Lei no 13.005, de 25 de junho de 2014, que aprovou o PNE 2014-2024, pois apresenta em seu Artigo 2으, as diretrizes desse Plano, dentre elas, temos a V, a qual se refere à formação relacionada para preparação do trabalho: "formação para o trabalho e para a cidadania, com ênfase nos valores morais e éticos em que se fundamenta a sociedade". (BRASIL, 2014).

Contudo, a concretização dessa diretriz aparece nas metas 10 e 11 que dizem respeito, respectivamente, à Educação de jovens e adultos, nos ensinos fundamental e médio, na forma integrada à educação profissional, e à Educação Profissional técnica de nível médio.

A Meta 10 estabelece a oferta de, no mínimo, 25\% das matrículas de educação de jovens e adultos, nos ensinos fundamental e médio, na forma integrada à educação profissional. Sobre essa Meta, Gracindo (2011) comenta:

Essa meta tem significativa importância no contexto geral das ações estabelecidas para a EJA. Isso porque torna visível a necessidade de aproximar a formação geral da formação profissional para estudantes da EJA, dadas suas peculiaridades e necessidades emergenciais de ingresso no mercado de trabalho. Assim, promover esforços a fim de garantir profissionalização, seja de nível básico ou de nível médio, para o segmento social atendido pela EJA é fundamental. Nesse sentido, são fundamentais: diversificação curricular; educação a distância; assistência aos estudante; envolvimento das entidades de formação profissional vinculadas ao sistema sindical.(GRACINDO, 2011, p.148,149).

No entanto, observando os dados referentes às matrículas na EJA efetuadas em 2013 no Ensino Fundamental (EF) e no Ensino Médio (EM), e estes níveis integrados ao Ensino Médio, vemos que o porcentual total de matrículas é de 3, 93\% (0,82\% no EF e 3,11\% no EM), conforme demonstra a Tabela 1 a seguir, com dados por região.

Percebemos pelos dados apresentados que a região nordeste se destaca na oferta de EJA integrada à Educação Profissional. Porém, tais números fornecidos não são suficientes para garantir que a proporção de $3,11 \%$ no número de matrículas para esta modalidade aconteça a cada ano, no decênio de 2014 a 2024, se não ocorrerem políticas públicas que mais do que assegurar as matrículas desse público, garantam a sua permanência para concluírem os cursos que os 
preparem, numa perspectiva humana integrada, para o mundo do trabalho e, ao mesmo tempo, elevem sua escolaridade.

Tabela 1: Total de matrículas e matrículas na EJA integrada à Educação Profissional Ensinos Fundamental e Médio - Brasil e regiões -2013

\begin{tabular}{l|c|c|c|c|c|c|c}
\hline \multirow{2}{*}{} & \multirow{2}{*}{ Total EJA } & \multicolumn{2}{|c|}{ Nível Fundamental } & \multicolumn{3}{c}{ Nível Médio } \\
\cline { 3 - 8 } & & Total & A & B & Total & A & B \\
\hline Brasil & $\mathbf{3 . 7 7 2 . 6 7 0}$ & $\mathbf{2 . 4 4 7 . 7 9 2}$ & $\mathbf{2 0 . 1 9 4}$ & $\mathbf{0 , 8 2}$ & $\mathbf{1 . 3 2 4 . 8 7 8}$ & $\mathbf{4 1 . 2 6 9}$ & $\mathbf{3 , 1 1}$ \\
\hline Norte & 499.605 & 357.374 & 2.270 & 0,64 & 142.231 & 4.107 & 2,89 \\
\hline Nordeste & 1.514 .727 & 1.143 .437 & 16.617 & 1,45 & 371.290 & 25.979 & 7,00 \\
\hline Sudeste & 1.149 .289 & 608.140 & 549 & 0,09 & 541.149 & 6.379 & 1,18 \\
\hline Sul & 356.609 & 200.791 & 443 & 0,22 & 155.818 & 3.037 & 1,95 \\
\hline Centro- Oeste & 252.440 & 138.050 & 315 & 0,23 & 114.390 & 1.767 & 1,54 \\
\hline
\end{tabular}

$A=$ Integrada à Educação Profissional

$\mathrm{B}=\%$ de matrículas quando integrado à Educação Profissional

Fonte: MEC/Inep/DEED - Sinopse Estatística da Educação Básica.

Nota: O mesmo aluno pode ter mais de uma matrícula.

As onze estratégias direcionadas ao cumprimento da Meta 10 dizem respeito à questões das especificidades desses sujeitos jovens e adultos (populações itinerantes e do campo, e das comunidades indígenas e quilombolas, bem como as privadas de liberdade nos estabelecimentos penais), à diversificação curricular, à formação continuada de docentes, à ações do programa nacional de assistência ao estudante e ao reconhecimento de saberes, a serem considerados na articulação curricular dos cursos oferecidos. Destaca-se também a manutenção de programa nacional de Educação de Jovens e Adultos voltado à conclusão do ensino fundamental e à formação profissional ${ }^{3}$.

Assim, mais do que garantir o aumento do número de acesso de jovens e adultos a uma educação integrada à Educação Profissional, é fundamental políticas públicas eficazes e a adoção de projetos pedagógicos diferenciados e específicos, capazes de atender à enorme diversidade do público que demanda por essa modalidade de ensino, evitando-se, assim, a evasão. E essas questões, as estratégias abarcam; temos, então, que atentarmos aos prazos e cobrarmos dos responsáveis a sua aplicabilidade.

Esperamos que, de fato, o Plano Nacional de Educação vigente, sobretudo, no que se refere a Meta 10, direcione ações em que a concepção de homem, mundo, trabalho e educação, não vise atender a lógica social do capitalismo nem aos organismos internacionais atrelados aos interesses hegemônicos. Diferentemente, de outras políticas voltadas para a EJA que apontavam para a continuidade da lógica de conformação à ordem social capitalista, servindo como forma de apaziguamento social e resposta ao processo de acumulação flexível, diante dos perigos do desemprego estrutural. Para isso, devem ser monitoradas e avaliadas, bem como sua implantação deve passar por processos de avaliação e redefinição.

\footnotetext{
${ }^{3}$ Destacam-se programas como: o Programa Nacional de Integração da Educação Profissional com a Educação Básica na Modalidade de Educação de Jovens e Adultos (PROEJA), aprovado em 2005; o Programa Brasil Profissionalizado, criado em 2007; o Programa Nacional de Acesso ao Ensino Técnico e Emprego (PRONATEC), instituído em 2012.
} 


\section{CONSIDERAÇÕES FINAIS}

A Constituição Federal assegura o acesso à educação básica àqueles que não tiveram a oportunidade de cursá-la na idade própria (C.F. art. 208, I). Assim, dada a importância da educação de jovens e adultos no contexto da dívida histórica que o Estado construiu diante da sociedade, vemos a necessidade urgente de promover a EJA como uma educação inclusiva pautada nos direitos humanos e no reconhecimento da diversidade, assim como o princípio do direito de aprender, ampliando conhecimentos ao longo da vida e não apenas sua faceta de escolarização.

Efetivar o direito à educação de jovens e dos adultos ultrapassa a perspectiva de ampliação da oferta de vagas nos sistemas públicos. Faz-se necessário, como já aponta algumas estratégias do PNE vigente, que a organização curricular, os projetos pedagógicos, a vinculação entre saberes a serem construídos e as práticas pedagógicas considerem sua identidade, saberes, cultura e valores próprios desses sujeitos.

Porém, muitos são os desafios para que as propostas apresentadas pelos Planos Nacionais de Educação sejam efetivadas. Dentre eles, estão o regime de colaboração entre os entes federados, que permita superar a desarticulação de iniciativas, a imposição de programas federais pré-moldados, sem o necessário respaldo técnico e financeiro pelos municípios da União e dos estados. É fundamental que não haja estratégia isolada para a modalidade, e, sim, um planejamento sistêmico que articule os planos nacionais, estaduais e municipais de Educação.

\section{REFERÊNCIAS}

1. BRASIL. Lei de Diretrizes e Bases da Educação Nacional - LDB Lei no 9394/96.

2. BRASIL. Conselho Nacional de Educação. Parecer CNE/CEB no 11/2000. Diretrizes Curriculares para a Educação de Jovens e Adultos. Brasília, MEC, maio 2000.

3. BRASIL. PROEJA - Programa Nacional de Integração da Educação Profissional com a Educação Básica na Modalidade de EJA: Formação Inicial e Continuada/Ensino Fundamental. Brasília: MEC, 2007.

4. BRASIL. Exposição de Motivos no 33. Subchefia de Assuntos Parlamentares. Brasília, MEC, novembro 2010.

5. BRASIL. Lei no 10.172, de 09 de janeiro de 2001. Aprova o Plano Nacional de Educação e dá outras providências. Brasília, 2001.

6. BRASIL. Lei $\mathrm{n} 013.005$, de 25 de junho de 2014. Aprova o Plano Nacional de Educação - PNE e dá outras providências. Brasília, 2014.

7. CHRISTOFOLI, Maria C.P. A sala de aula como espaço rico de aprendizagem ou do óbvio. In SCHWARTZ, Suzana. Alfabetização de Jovens e Adultos: teoria e prática. Rio de Janeiro: Vozes, 2010.

8. DI PIERRO, Maria Clara. A Educação de Jovens e Adultos no Plano Nacional de Educação: avaliação, desafios e perspectivas. Educação \& Sociedade. Campinas, v.31, n.112, p.939-959, jul-set.2010.

9. DOURADO, L. F. Avaliação do Plano Nacional de Educação 2001-2009: questões estruturais e conjunturais de uma política. Educação \& Sociedade, Campinas, v.31, n.112,pp.677-705, jul.- 
set.2010.

10. GRACINDO, Regina Vinhaes. A educação de jovens e adultos e o PNE 2011-2020: Avaliação e perspectivas. In: DOURADO, L.F. (Org.) Plano Nacional de Educação (2011-2020): avaliação e perspectivas. 2.ed. Goiânia: Editora UFG, 2011.

11. HORTA, José Silvério Baia. Liberalismo, Tecnocracia e Planejamento Educacional no Brasil. São Paulo: Cortez/ Autores Associados, 1982.

12. JARDILINO, José Rubens Lima; ARAÚJO, Regina Magna Bonifácio de. Educação de Jovens e Adultos: sujeitos, saberes e práticas. 1.ed. São Paulo: Cortez, 2014. (Coleção docência em formação: Educação de jovens e adultos).

13. MENDONÇA, E.F. Plano Nacional de Educação: desdobramentos na política educacional. In: TEIXEIRA,L.H.G.(org.) LDB e PNE: desdobramentos na política educacional brasileira. São Bernardo do Campo: Umesp, 2002.

14. OLIVEIRA, Ramon de. (Org.). Jovens, ensino médio e educação profissional: políticas públicas em debate. São Paulo: Papirus, 2012.

15. POULANTZAS, N. O Estado, o poder, o socialismo. 4 ed. Rio de Janeiro: Graal, 2000.

16. SANTOS, Maria das Graças dos. Políticas públicas: contribuições para o debate. KANAANE, Roberto; FILHO, Alécio Fiel; Ferreira, Maria das Graças (orgs.). Gestão pública: planejamento, processos, sistemas de informações e pessoas. São Paulo: Atlas, 2010, p. 3-15.

17. SAVIANI, D. Da nova LDB ao novo Plano Nacional de Educação: por uma política educacional. Campinas: Autores Associados, 1998.

18. VALENTE, Ivan; ROMANO, Roberto. PNE: Plano Nacional de Educação ou carta de intenção?. Educação \& Sociedade, Campinas, v. 23, n. 80, p. 96-107, 2002. 